\title{
Mechanical circulatory support for refractory out-of-hospital cardiac arrest: a Danish nationwide multicenter study
}

Sivagowry Rasalingam Mørk ${ }^{1 *}$, Carsten Stengaard ${ }^{1}$, Louise Linde², Jacob Eifer Møller², Lisette Okkels Jensen ${ }^{2}$, Henrik Schmidt ${ }^{3}$, Lars Peter Riber ${ }^{4}$, Jo Bønding Andreasen ${ }^{5}$, Sisse Anette Thomassen ${ }^{5}$, Helle Laugesen ${ }^{5}$, Phillip Michael Freeman ${ }^{6}$, Steffen Christensen ${ }^{7}$, Jacob Raben Greisen ${ }^{7}$, Mariann Tang ${ }^{8}$, Peter Hasse Møller-Sørensen ${ }^{9}$, Lene Holmvang ${ }^{10}$, Emilie Gregers ${ }^{10}$, Jesper Kjaergaard ${ }^{10}$, Christian Hassager $^{10}$, Hans Eiskjær ${ }^{1}$ and Christian Juhl Terkelsen ${ }^{1,11}$

\begin{abstract}
Background: Mechanical circulatory support (MCS) with either extracorporeal membrane oxygenation or Impella has shown potential as a salvage therapy for patients with refractory out-of-hospital cardiac arrest (OHCA). The objective of this study was to describe the gradual implementation, survival and adherence to the national consensus with respect to use of MCS for OHCA in Denmark, and to identify factors associated with outcome.

Methods: This retrospective, observational cohort study included patients receiving MCS for OHCA at all tertiary cardiac arrest centers $(n=4)$ in Denmark between July 2011 and December 2020. Logistic regression and Kaplan-Meier survival analysis were used to determine association with outcome. Outcome was presented as survival to hospital discharge with good neurological outcome, 30-day survival and predictors of 30-day mortality.

Results: A total of 259 patients were included in the study. Thirty-day survival was $26 \%$. Sixty-five (25\%) survived to hospital discharge and a good neurological outcome (Glasgow-Pittsburgh Cerebral Performance Categories 1-2) was observed in $94 \%$ of these patients. Strict adherence to the national consensus showed a 30-day survival rate of 30\% compared with $22 \%$ in patients violating one or more criteria. Adding criteria to the national consensus such as signs of life during cardiopulmonary resuscitation (CPR), pre-hospital low-flow $<100 \mathrm{~min}, \mathrm{pH}>6.8$ and lactate $<15 \mathrm{mmol} / \mathrm{L}$ increased the survival rate to $48 \%$, but would exclude $58 \%$ of the survivors from the current cohort. Logistic regression identified asystole (RR 1.36, 95\% Cl 1.18-1.57), pulseless electrical activity (RR 1.20,95\% Cl 1.03-1.41), initial pH $<6.8$ (RR $1.28,95 \% \mathrm{Cl} 1.12-1.46$ ) and lactate levels $>15 \mathrm{mmol} / \mathrm{L}$ (RR 1.16, 95\% Cl 1.16-1.53) as factors associated with increased risk of 30-day mortality. Patients presenting signs of life during CPR had reduced risk of 30-day mortality (RR 0.63, 95\% Cl 0.52-0.76).
\end{abstract}

Conclusions: A high survival rate with a good neurological outcome was observed in this Danish population of patients treated with MCS for OHCA. Stringent patient selection for MCS may produce higher survival rates but potentially withholds life-saving treatment in a significant proportion of survivors.

*Correspondence: sivarasa@rm.dk

1 Department of Cardiology, Aarhus University Hospital, Palle Juul-Jensens

Boulevard 99, 8200 Aarhus N, Denmark

Full list of author information is available at the end of the article original author(s) and the source, provide a link to the Creative Commons licence, and indicate if changes were made. The images or other third party material in this article are included in the article's Creative Commons licence, unless indicated otherwise in a credit line to the material. If material is not included in the article's Creative Commons licence and your intended use is not permitted by statutory regulation or exceeds the permitted use, you will need to obtain permission directly from the copyright holder. To view a copy of this licence, visit http://creativecommons.org/licenses/by/4.0/. The Creative Commons Public Domain Dedication waiver (http://creativeco mmons.org/publicdomain/zero/1.0/) applies to the data made available in this article, unless otherwise stated in a credit line to the data. 
Keywords: Out-of-hospital cardiac arrest, Mechanical circulatory support, Extracorporeal membrane oxygenation, Impella, Cardiopulmonary resuscitation

\section{Background}

Out-of-hospital cardiac arrest (OHCA) is a time-critical condition associated with a high mortality worldwide. Despite various initiatives to improve public engagement and ensure access to a sufficient number of external defibrillators, survival rates remain poor [1]. Short-term mechanical circulatory support (MCS) with extracorporeal membrane oxygenation (ECMO) or Impella devices has emerged as a rescue therapy in adult patients with OHCA that is refractory to conventional cardiopulmonary resuscitation (CPR). MCS may ensure life-saving organ perfusion, lending clinicians crucial time to identify and treat the underlying cause of cardiac arrest. Extracorporeal cardiopulmonary resuscitation (ECPR) refers to the rapid application of ECMO in the setting of refractory cardiac arrest. Several observational studies and recently one randomized clinical trial have demonstrated encouraging results after ECPR [2-6]. In recent years, the use of Impella devices as MCS for refractory OHCA have also shown potential in this high-risk population [7, 8]. Although the field of MCS for refractory cardiac arrest has evolved rapidly over the past decades, identifying optimal candidates is still an inevitable challenge.
MCS for refractory OHCA has been introduced gradually over the past ten years in Denmark, and a national consensus was adopted in February 2018 [9]. However, detailed knowledge of the full cohort treated remains scarce. Regional differences in triage of patients with OHCA may influence the availability of MCS, which may in turn affect patient selection and outcome. The aims of this study were to describe temporal trends and regional variation in the use of MCS in Denmark, to evaluate adherence to the national consensus on ECPR use and to identify factors associated with outcome.

\section{Methods}

This nationwide retrospective, observational cohort study was conducted at four tertiary cardiac arrest centers in Denmark (Aalborg University Hospital, Aarhus University Hospital, Odense University Hospital and Copenhagen University Hospital). In Denmark, MCS for refractory OHCA is performed at these four centers exclusively.

\section{National consensus}

The Danish national consensus on the use of ECPR in patients with refractory OHCA was adopted in February 2018 [9] (Fig. 1, Consensus A-National consensus).

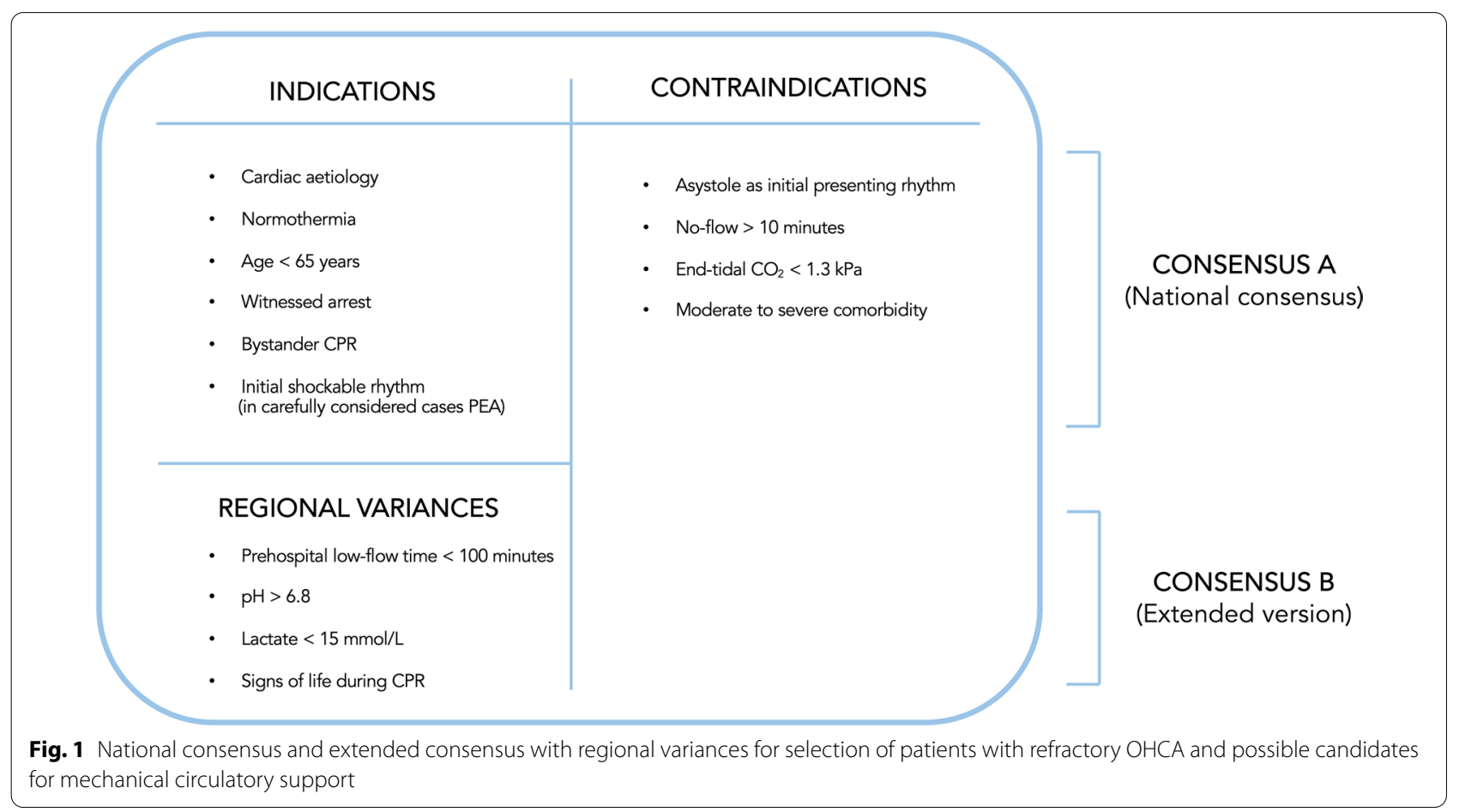


The most consistent criteria for inclusion were normothermic cardiac arrest with a presumed cardiac origin, age $<65$ years, an initial shockable rhythm, witnessed arrest, bystander $\mathrm{CPR}$ and end-tidal $\mathrm{CO}_{2}>1.3 \mathrm{kPa}$. Regional differences in the inclusion criteria were present during the study period as shown in Fig. 1, Consensus B-Extended version and Additional file 1: Table S1.

\section{Study population}

The study population included all patients aged $\geq 18$ years receiving MCS for refractory OHCA, which was defined as absence of return of spontaneous circulation (ROSC) despite resuscitation efforts for more than $15 \mathrm{~min}$. Patients treated between July 2011 and December 2020 were identified from local MCS databases and medical records. Due to regional differences in MCS availability and updates to databases, the data collection period differed for each hospital: Aalborg University Hospital (February 2016-December 2020), Aarhus University Hospital (July 2011-December 2020), Odense University Hospital (November 2015-December 2020) and Copenhagen University Hospital (November 2016-December 2020).

\section{Study setting}

Patient selection, triage, and implementation of either Impella or ECPR were performed at the discretion of the treating ECPR team at the individual centers. The specialized ECPR teams, including anaesthesiologists, cardiothoracic surgeons, perfusionists, and invasive and general cardiologists managed all patients upon arrival at the catherization laboratory. Venoarterial ECMO cannulations were inserted percutaneously using the Seldinger technique with ultrasound guidance. In case of unsuccessful percutaneous cannulation, open cut-down technique with direct visualization of the femoral vein and artery was performed. Vascular access was achieved by $15 \mathrm{~F}-23 \mathrm{~F}$ arterial cannulas and $19 \mathrm{~F}-26 \mathrm{~F}$ venous cannulas. In the majority of patients, a distal arterial perfusion cannula was inserted to ensure antegrade limb perfusion. Circuit flow was titrated until effective circulatory response was achieved. Fluid, inotropes and vasopressors were applied if necessary. ECPR was achieved in most cases; however, in a minority of patients, the Impella device was initially employed if visible spontaneous cardiac contractility was observed on echocardiography during rhythm check. The Impella device was placed percutaneously in the femoral artery, and correct positioning was then confirmed by fluoroscopy or echocardiography. ECPR in combination with Impella was applied in patients with failing cardiac recovery immediately after ECPR initiation or within $24 \mathrm{~h}$ after. Combined use of ECPR and Impella was initiated to ensure aortic valve opening and sufficient left ventricular unloading.
For both ECPR- and Impella-treated patients, unfractionated heparin was administrated routinely to avoid systemic clotting and aiming for an activated partial thromboplastin time of $60-80 \mathrm{~s}$ or an activated clotting time of $160-180 \mathrm{~s}$.

Post-resuscitation care and management were performed according to local intensive care unit (ICU) standard protocols including targeted temperature management (TTM), neurological prognostication and procedures for withdrawal of treatment. Weaning from MCS was done if cardiac and respiratory function were considered to have recovered sufficiently or if further treatment was deemed futile [10].

\section{Data collection}

Study data were recorded in a uniform national database. A study coordinator from each hospital was assigned to manage the data collection. According to the Utstein recommendation for data collection [11], information on cardiac arrest was acquired from the pre-hospital emergency medical service logistic systems and included information on: time of cardiac arrest, witnessed arrest, bystander CPR, initial rhythm and pre-hospital care comprising inotropic usage and intubation. Patient demographics and in-hospital data on clinical parameters, known comorbidities, laboratory tests, intervention and outcome data were obtained from patient records.

\section{Study end-points}

The primary end-point was 30-day survival. Secondary end-points included survival to hospital discharge, neurological outcome at hospital discharge and regional differences in triage and outcome. Neurological outcome was evaluated by the Glasgow-Pittsburgh Cerebral Performance Categories (CPC), and a favorable outcome was defined as CPC scores 1 and 2 [12].

\section{Statistical analysis}

Continuous data are presented as median and interquartile range (IQR, $\mathrm{P}_{25}-\mathrm{P}_{75}$ ) and categorical data as number and percentages. The Mann-Whitney $U$ test and the Kruskal-Wallis $\mathrm{H}$ test were used for comparison of continuous data, whereas the chi-squared test and Fisher's exact test were used for categorical data. Logistic regression was performed to assess the association of risk factors on 30-day mortality. Results are expressed as risk ratio (RR) and 95\% confidence interval (CI). Risk factors were identified a priori based on their clinical relevance and previously published literature. Survival analysis results are presented as Kaplan-Meier curves for various subgroups of patients and compared with the log rank test. In case of missing values, patients were excluded from the statistical analysis. Two-sided p-values of $<0.05$ 
were considered statistically significant. Statistical tests were performed using STATA/IC 16, College Station TX77845, USA, for Mac.

\section{Results}

Additional file 2: Figure S1 demonstrates the gradual implementation of MCS in Denmark. Between July 2011 and December 2020, a total of 259 patients treated with MCS for OHCA were enrolled in the study: (Aalborg University Hospital, $\mathrm{n}=34$, Aarhus University Hospital, $\mathrm{n}=138$, Odense University Hospital, $\mathrm{n}=55$, and Copenhagen University Hospital, $\mathrm{n}=32$ ). Survival to day 30 was seen in $67(26 \%)$. A total of $65(25 \%)$ patients survived to hospital discharge, and 61 (94\%) of these patients were discharged with a CPC of 1-2.

\section{Baseline and cardiac arrest characteristics}

Baseline and arrest characteristics are summarized in Table 1. The median age of the study population was 53 years (IQR, $45-60$ years), and $79 \%$ were men.

Table 1 Baseline characteristics and pre-hospital data stratified by 30-day survival status

\begin{tabular}{|c|c|c|c|c|}
\hline Variable & $\begin{array}{l}\text { Total } \\
(n=259)\end{array}$ & $\begin{array}{l}\text { Survivors } \\
(n=67)\end{array}$ & $\begin{array}{l}\text { Non-survivors } \\
(n=192)\end{array}$ & $P$-value \\
\hline Age (years) & $53[45-60]$ & $54[46-62]$ & $53[43-59]$ & 0.19 \\
\hline Age $\leq 65$ years & $221(85)$ & $56(84)$ & $165(86)$ & 0.64 \\
\hline Male sex & $205(79)$ & $50(75)$ & $155(81)$ & 0.29 \\
\hline \multicolumn{5}{|l|}{ Comorbidities } \\
\hline History of ischemic heart disease & $30(12)$ & $9(13)$ & $21(11)$ & 0.58 \\
\hline Previous myocardial infarction & $28(11)$ & $8(12)$ & $20(11)$ & 0.75 \\
\hline History of congestive heart disease & $19(7)$ & $4(6)$ & $15(8)$ & 0.62 \\
\hline Hypertension & $65(25)$ & $18(27)$ & $47(25)$ & 0.73 \\
\hline Type 2 diabetes & $26(10)$ & $3(5)$ & $23(12)$ & 0.06 \\
\hline Peripheral vascular disease & $11(4)$ & $4(6)$ & $7(4)$ & 0.31 \\
\hline Previous chronic kidney disease & $8(3)$ & $2(3)$ & $6(3)$ & 0.65 \\
\hline Previous stroke & $10(4)$ & $0(0)$ & $10(5)$ & 0.05 \\
\hline \multicolumn{5}{|l|}{ Cause of cardiac arrest } \\
\hline Acute myocardial infarction & $142(55)$ & $42(63)$ & $100(52)$ & 0.13 \\
\hline Pulmonary embolism & $24(9)$ & $8(12)$ & $16(8)$ & 0.26 \\
\hline Primary arrhythmia & $42(16)$ & $10(15)$ & $32(17)$ & 0.85 \\
\hline Chronic heart disease & $5(2)$ & $1(2)$ & $4(2)$ & 1.00 \\
\hline Cerebral & $6(2)$ & $0(0)$ & $6(3)$ & 0.34 \\
\hline Toxic & $10(4)$ & $3(5)$ & $7(4)$ & 0.72 \\
\hline Other & $20(8)$ & $4(6)$ & $16(8)$ & 0.79 \\
\hline Unknown & $13(4)$ & $0(0)$ & $13(5)$ & 0.02 \\
\hline Witnessed arrest & $223(86)$ & $60(90)$ & $163(85)$ & 0.34 \\
\hline Bystander CPR & $246(95)$ & $64(96)$ & $182(95)$ & 0.94 \\
\hline Transient ROSC & $48(19)$ & $27(40)$ & $21(11)$ & $<0.001$ \\
\hline Signs of life during CPR & $100(39)$ & $45(67)$ & $55(29)$ & $<0.001$ \\
\hline \multicolumn{5}{|l|}{ Initial presenting rhythm } \\
\hline Shockable (VTNF) & $173(67)$ & $55(82)$ & $118(62)$ & 0.002 \\
\hline PEA & $57(22)$ & $10(15)$ & $47(25)$ & 0.10 \\
\hline Asystole & $28(11)$ & $2(3)$ & $26(14)$ & 0.02 \\
\hline End-tidal $\mathrm{CO}_{2}$ & $3.6[2.8-5.0]$ & $3.6[2.9-5.0]$ & $3.5[2.5-5.0]$ & 0.99 \\
\hline Mechanical compression (LUCAS) & $235(91)$ & $61(91)$ & $174(91)$ & 0.97 \\
\hline No-flow (min) & $0[0-1]$ & $0[0-2]$ & $0[0-1]$ & 0.77 \\
\hline Pre-hospital low-flow (min) & $72[58-90]$ & $67[46-90]$ & $75[60-90]$ & 0.06 \\
\hline Total low-flow (min) & $105[86-125]$ & $94[73-120]$ & $107[90-127]$ & 0.002 \\
\hline
\end{tabular}

Abbreviations: CPR Cardiopulmonary resuscitation; ROSC Return of spontaneous circulation; VTVentricular tachycardia; VF Ventricular fibrillation; PEA Pulseless electrical activity; LUCAS Lund University cardiopulmonary assist system

Values are stated as medians and interquartile range $[\mathrm{IQR}]$ or numbers and percentages. A $p$ value $<0.05$ is considered significant 
No significant differences in comorbidities were seen between survivors and non-survivors. In most cases, arrest aetiology was of cardiac origin; and the three dominant causes were acute myocardial infarction $(\mathrm{n}=142,55 \%)$, primary arrhythmia $(\mathrm{n}=42,16 \%)$ and pulmonary embolism $(n=24,9 \%)$. Significantly more survivors than non-survivors presented an initial shockable rhythm $(\mathrm{p}=0.002)$ and signs of life during conventional CPR $(\mathrm{p}<0.001)$. Witnessed cardiac arrest was present in 223 (86\%) of the patients, and 246 (95\%) patients received bystander CPR initiated immediately after recognition of arrest with a median no-flow time of $0 \mathrm{~min}$ (IQR, 0-1 min). Survivors experienced a significantly shorter total low-flow time from cardiac arrest to MCS initiation than non-survivors (94 $\mathrm{min}$ versus $107 \mathrm{~min}, \mathrm{p}=0.002$ ).

\section{In-hospital and outcome characteristics}

In-hospital and outcome data are shown in Table 2. ECPR was established in 225 (86.9\%) patients, whereas Impella assistance was commenced in $12(4.6 \%)$ patients. Twenty-two patients $(8.5 \%)$ received concomitant support (ECPR + Impella). Among the 247 patients treated with ECPR, cannulation was done percutaneously in 224 patients and by cut-down in 23 patients. Distal perfusion was established in 179 of the ECPR patients. Acute coronary angiography was performed in $234(90 \%)$ patients, and $124(48 \%)$ of the patients received percutaneous coronary intervention. Survivors more likely presented advantageous blood gas analysis with higher median $\mathrm{pH}$ levels $(7.01$ versus $6.88, \mathrm{p}<0.001)$ and lower serum lactate levels $(12.0 \mathrm{mmol} / \mathrm{L}$ versus $15.0 \mathrm{mmol} / \mathrm{L}, \mathrm{p}<0.001)$ prior to MCS implantation. The majority of the patients $(\mathrm{n}=218 ; 84 \%)$ were admitted directly to the ICU after

Table 2 In-hospital data stratified by 30-day survival status

\begin{tabular}{|c|c|c|c|c|}
\hline Variable & $\begin{array}{l}\text { Total } \\
(n=259)\end{array}$ & $\begin{array}{l}\text { Survivors } \\
(n=67)\end{array}$ & $\begin{array}{l}\text { Non-survivors } \\
(\mathrm{n}=192)\end{array}$ & P-value \\
\hline ECMO (only) & $225(86.9)$ & $55(82)$ & $170(89)$ & 0.18 \\
\hline Impella (only) & $12(4.6)$ & $6(9)$ & $6(3)$ & 0.05 \\
\hline $\mathrm{ECMO}+$ Impella & $22(8.5)$ & $6(9)$ & $16(8)$ & 0.88 \\
\hline \multicolumn{5}{|l|}{ Laboratory data upon arrival } \\
\hline $\mathrm{pH}$ & $6.90[6.82-7.02]$ & $7.01[6.92-7.15]$ & $6.88[6.80-6.98]$ & $<0.001$ \\
\hline Lactate $(\mathrm{mmol} / \mathrm{L})$ & $14.4[11.4-17.0]$ & $12.0[9.1-14.7]$ & $15.0[12.0-19.0]$ & $<0.001$ \\
\hline Potassium (mmol/L) & $4.4[3.7-5.4]$ & $4.1[3.6-4.9]$ & $4.6[3.8-5.5]$ & 0.06 \\
\hline Hemoglobin (mmol/L) & $8.6[7.5-9.6]$ & $8.7[8.1-9.6]$ & $8.6[7.3-9.6]$ & 0.22 \\
\hline Creatinine (mmol/L) & $114[98-130]$ & $109[95-131]$ & 115 [99-130] & 0.86 \\
\hline CAG performed & $234(90)$ & $62(93)$ & $172(90)$ & 0.48 \\
\hline Coronary intervention ( $\mathrm{PCl} /$ stent) & $124(48)$ & $37(55)$ & $87(46)$ & 0.20 \\
\hline Left main & $22(9)$ & $5(8)$ & $17(10)$ & 0.73 \\
\hline Left anterior descending & $76(33)$ & $27(44)$ & $49(29)$ & 0.02 \\
\hline Left circumflex & $8(3)$ & $2(3)$ & $6(4)$ & 0.96 \\
\hline Right coronary artery & $30(13)$ & $9(15)$ & $21(12)$ & 0.58 \\
\hline \multicolumn{5}{|l|}{ Intensive care stay } \\
\hline No. of patients admitted to ICU & $218(84)$ & $67(100)$ & $151(79)$ & $<0.001$ \\
\hline TTM & $152(70)$ & $46(69)$ & $106(70)$ & 0.46 \\
\hline Renal replacement therapy & $91(42)$ & $32(48)$ & $59(31)$ & 0.27 \\
\hline ICU length of stay (hours) & $53[13-238]$ & $284[163-528]$ & 19 [10-63] & $<0.001$ \\
\hline \multicolumn{5}{|l|}{ ECPR-/Impella-related complications } \\
\hline Bleeding at cannulation site & $76(29)$ & $32(48)$ & $44(23)$ & 0.01 \\
\hline Limb ischemia & $24(9)$ & $5(8)$ & $19(10)$ & 0.31 \\
\hline Gastrointestinal bleeding & $33(13)$ & $10(15)$ & $23(12)$ & 0.90 \\
\hline Gastrointestinal ischemia & $22(9)$ & $4(6)$ & $18(9)$ & 0.20 \\
\hline Time on ECPR (hours) & 50 [27-95] & $67[40-98]$ & $37[8-77]$ & 0.002 \\
\hline Time on Impella (hours) & $74[28-165]$ & $62[50-165]$ & 84 [10-166] & 0.46 \\
\hline Hospital length of stay (hours) & $23[7-358]$ & $687[496-1060]$ & $13[4-46]$ & $<0.001$ \\
\hline
\end{tabular}

Abbreviations: ECMO Extracorporeal membrane oxygenation; CAG Coronary angiogram; PCI Primary coronary intervention; ICU Intensive care unit; TTM Target temperature management

Values are stated as medians and interquartile range (IQR) or numbers and percentages. A p- value of $<0.05$ is considered significant 
MCS commencement. However, in 41 (16\%) patients, further resuscitation efforts were deemed futile and treatment was withdrawn before admission to the ICU. The main reasons for terminating treatment were anoxic brain injury after cardiac arrest or intracerebral haemorrhage, extensive bleeding due to either acute aortic dissection or complication of Lund University Cardiopulmonary Assist System (LUCAS) with spleen or liver rupture, and severe heart failure despite inotropes and vasopressor support.

No differences between the groups were seen regarding renal replacement therapy or TTM, $(p=0.27$ and $\mathrm{p}=0.46$, respectively). MCS duration and ICU length of stay were longer in survivors, indicating rapid withdrawal of support in the case of treatment futility. Bleeding at the cannulation site was observed in $76(29 \%)$ and limb ischemia was seen in $24(9 \%)$ of the patients. None of the patients without distal perfusion had limb ischemia. The main cause of withdrawal of life-sustaining treatment in non-survivors was severe brain injury $(\mathrm{n}=88,46 \%)$, no cardiac recovery $(n=25,13 \%)$, device failure $(n=4,2 \%)$, multiorgan failure $(n=49,26 \%)$ and other $(n=26,14 \%)$.

\section{Predictors of 30-day mortality and survival outcomes}

Table 3 shows results from the binary logistic regression. Thirty-day mortality was significantly associated with initial presenting rhythm with asystole (RR 1.36, 95\% CI 1.18-1.57, $\mathrm{p}<0.001$ ), pulseless electrical activity
(PEA) (RR 1.20, 95\% CI 1.03-1.41, $\mathrm{p}=0.02$ ), low $\mathrm{pH}$ levels $<6.8$ (RR 1.28, 95\% CI 1.12-1.46, $\mathrm{p}<0.001)$ and high lactate levels $>15 \mathrm{mmol} / \mathrm{L}$ (RR 1.33, 95\% CI 1.161.53, p < 0.001). Signs of life during CPR (RR 0.63, 95\% CI 0.52-0.76, $\mathrm{p}<0.001$ ) and transient ROSC (RR 0.54, $95 \%$ CI $0.39-0.76, \mathrm{p}<0.001)$ were both associated with a lower risk of mortality.

Kaplan-Meier curves and the log rank test demonstrated similar results (Additional file 3: Figure S2). Patients presenting signs of life during CPR had a higher survival rate compared to patients without signs of life $(45 \%$ versus $13 \%, \mathrm{p}<0.001)$, Fig. S2, B. A favorable 30-day survival was also seen in patients with a prehospital low-flow time $<60 \mathrm{~min}$ and in patients with a pre-hospital low-flow time $>80$ min $(40 \%$ versus $26 \%$ ), Fig. S2, C. Patients with a prolonged pre-hospital lowflow time $(>80 \mathrm{~min})$ had a higher rate of signs of life during CPR than patients with a pre-hospital low-flow time of $60-80 \mathrm{~min}(41 \%$ versus $31 \%, \mathrm{p}=0.14)$. For other subgroups, please refer to Additional files 2, 3: Figure S2 and Figure S3 for further 30-day survival data.

Figure 2 demonstrates Kaplan-Meier curves for patients with and without signs of life during CPR and their 30-day survival with respect to initial presenting rhythm and pre-hospital low-flow times. Patients with signs of life had significantly higher survival rates compared to patients with no signs of life for both entities. Patients presenting non-shockable rhythm without signs of life had no survivors at day 30.

Table 3 Binary logistic regression analysis of risk factors associated with 30-day mortality

\begin{tabular}{|c|c|c|c|c|}
\hline \multirow[t]{2}{*}{ Variables } & \multirow{2}{*}{$\begin{array}{l}\text { Number of valid cases } \\
\text { Total }(n=259)\end{array}$} & \multicolumn{3}{|c|}{ Univariate analysis } \\
\hline & & $\mathbf{R R}$ & $95 \% \mathrm{Cl}$ & P-value \\
\hline Age (years) & 259 & 1.00 & $(0.99-1.00)$ & 0.21 \\
\hline Male sex & 259 & 1.10 & $(0.90-1.34)$ & 0.34 \\
\hline Witnessed arrest & 259 & 0.91 & $(0.76-1.08)$ & 0.28 \\
\hline Bystander CPR & 259 & 0.98 & $(0.70-1.38)$ & 0.93 \\
\hline Initial presenting rhythm & 258 & & & \\
\hline VTNF* & & 1.00 & - & - \\
\hline PEA & & 1.20 & $(1.03-1.41)$ & 0.02 \\
\hline Asystole & & 1.36 & $(1.18-1.57)$ & $<0.001$ \\
\hline Signs of life during CPR & 251 & 0.63 & $(0.52-0.76)$ & $<0.001$ \\
\hline Transient ROSC & 252 & 0.54 & $(0.39-0.76)$ & $<0.001$ \\
\hline End-tidal $\mathrm{CO}_{2}$ & 224 & 0.82 & $(0.65-1.01)$ & 0.07 \\
\hline Pre-hospital low-flow $\leq 60 \mathrm{~min}$ & 259 & 0.80 & $(0.67-0.95)$ & 0.02 \\
\hline $\mathrm{pH} \leq 6.8$ & 236 & 1.28 & $(1.12-1.46)$ & $<0.001$ \\
\hline Lactate $\geq 15 \mathrm{mmol} / \mathrm{L}$ & 251 & 1.33 & $(1.16-1.53)$ & $<0.001$ \\
\hline
\end{tabular}

Abbreviations: CPR Cardiopulmonary resuscitation; VTVentricular tachycardia; VF Ventricular fibrillation; PEA Pulseless electrical activity; ROSC Return of spontaneous circulation; RR Risk ratio; Cl Confidence interval

*Reference group 
A

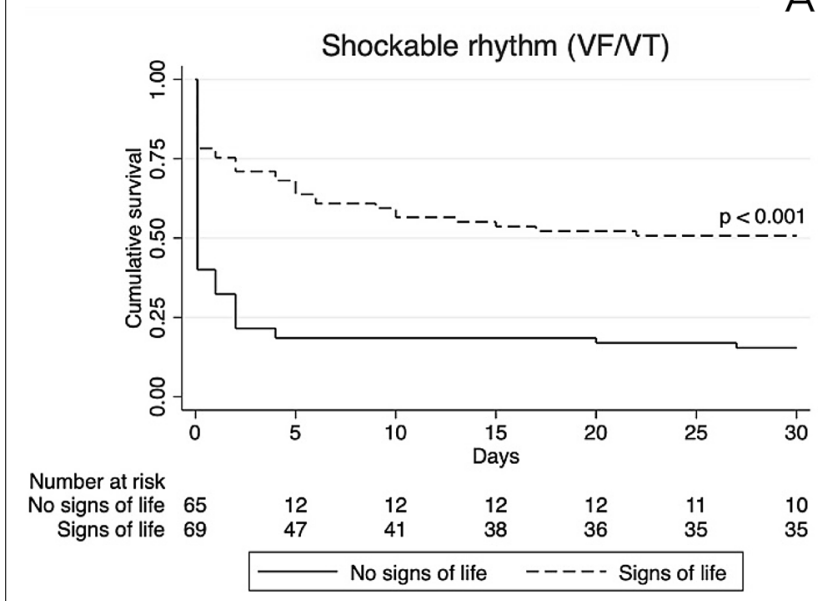

C

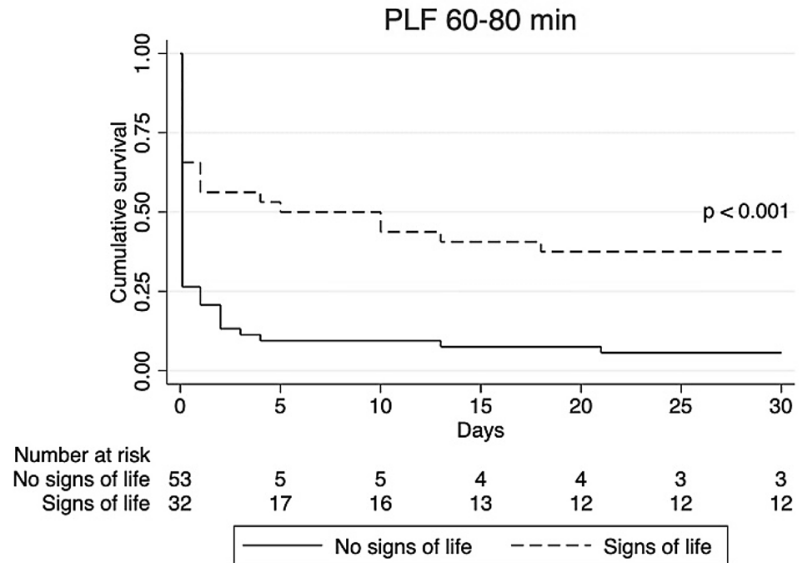

B

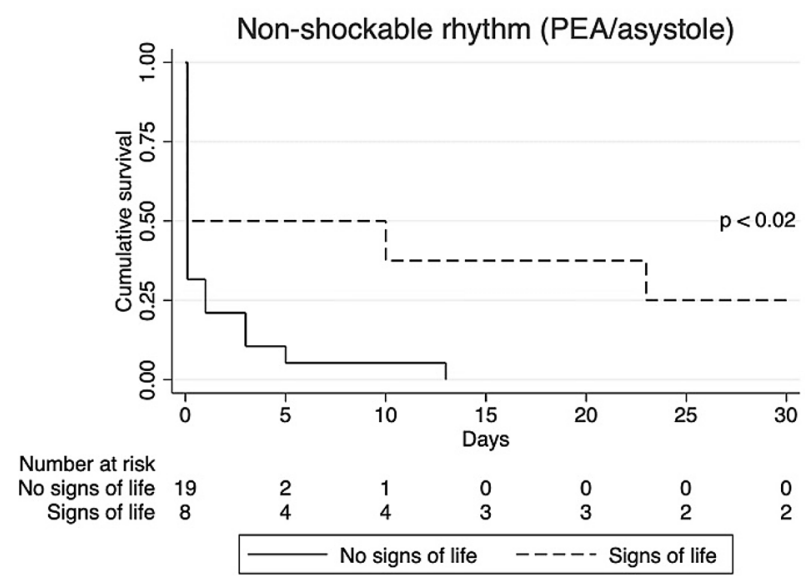

D

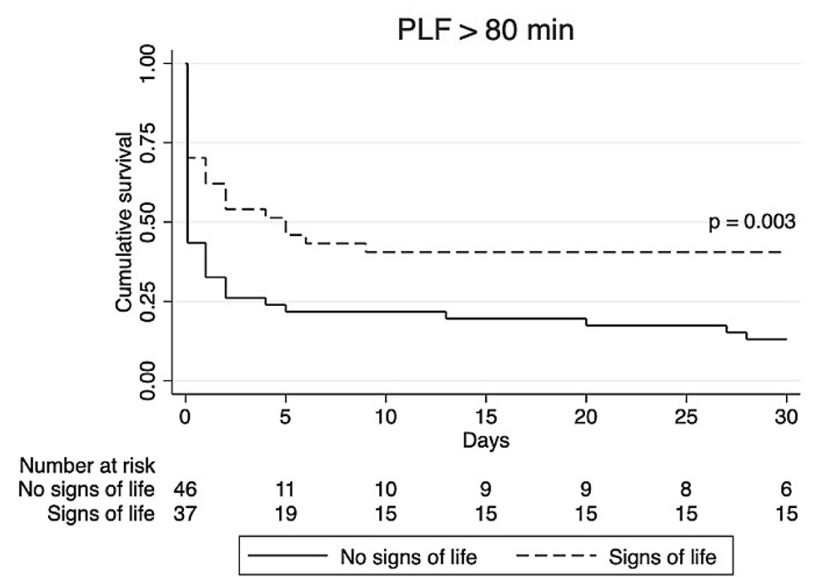

Fig. 2 Kaplan-Meier survival curves for patients with and without signs of life during cardiopulmonary resuscitation with respect to initial presenting rhythm and pre-hospital low-flow times. a Patients with initial shockable rhythm with signs of life and no signs of life. $\mathbf{b}$ Patients with non-shockable rhythm with signs of life and no signs of life. c Patients with pre-hospital low flow (PLF) 60-80 min with signs of life and no signs of life. $\mathbf{d}$ Patients with PLF $>80$ min with signs of life and no signs of life

\section{Regional differences}

Regional differences in patient selection and outcome are shown in Table 4. The ECPR activity per million inhabitants differed between centers. In most centers, younger age was a predominant factor for triage; nevertheless, 38 (15\%) patients with age $>65$ years did receive ECPR. Initial presenting rhythm differed significantly between centers $(p=0.003)$. Pre-hospital low-flow times were significantly longer $(77 \mathrm{~min}$ versus $60 \mathrm{~min}, \mathrm{p}=0.02$ ) in hospitals serving patients in remote and rural areas with a distance to center $>100 \mathrm{~km}$ $(\mathrm{p}=0.001)$. Thirty-day survival between centers varied from 15 to $28 \%$; however, this difference did not reach statistical significance, $\mathrm{p}=0.41$.

\section{Analysis of selection criteria in the Danish national consensus}

Figure 3 illustrates the survival rates of survivors to discharge with CPC $1-2(n=61)$ in regards to each selection criteria of the Danish 2018 national ECPR consensus. Poorest outcomes were seen in patients with initial nonshockable rhythm, no-flow times $>10 \mathrm{~min}$ and end-tidal $\mathrm{CO}_{2}<1.3 \mathrm{kPa}$.

Patients meeting all of the selection criteria of the Danish 2018 national ECPR consensus with respect to normothermic arrest of presumed cardiac origin, age $<65$ years, witnessed arrest, bystander CPR, initial shockable rhythm, no-flow time $<10 \mathrm{~min}$ and end-tidal $\mathrm{CO}_{2}<1.3 \mathrm{kPa}(\mathrm{n}=125,48 \%)$ were compared with those 
Table 4 Regional differences in triage and outcome of patients treated with extracorporeal cardiopulmonary resuscitation or Impella for refractory cardiac arrest

\begin{tabular}{|c|c|c|c|c|c|}
\hline Variable & $\begin{array}{l}\text { Aalborg University } \\
\text { Hospital } \\
(\mathrm{n}=34)\end{array}$ & $\begin{array}{l}\text { Aarhus University } \\
\text { Hospital } \\
(n=138)\end{array}$ & $\begin{array}{l}\text { Odense University } \\
\text { Hospital } \\
(n=55)\end{array}$ & $\begin{array}{l}\text { Copenhagen } \\
\text { University Hospital } \\
(n=32)\end{array}$ & P-value \\
\hline No. of MCS/mio-inhabitants*year & 11.6 & 11.2 & 8.9 & 2.8 & $<0.001$ \\
\hline Age $<65$ years & $26(76)$ & $113(82)$ & $51(93)$ & $31(97)$ & 0.03 \\
\hline Initial presenting rhythm & & & & & 0.003 \\
\hline Shockable VT/VF & $19(56)$ & $82(59)$ & $44(80)$ & $28(88)$ & \\
\hline PEA & $11(32)$ & $38(28)$ & $4(7)$ & $4(13)$ & \\
\hline Asystole & $3(9)$ & $18(13)$ & $7(13)$ & $0(0)$ & \\
\hline Unknown & $1(3)$ & $0(0)$ & $0(0)$ & $0(0)$ & \\
\hline Witnessed arrest & $31(91)$ & $114(83)$ & $49(89)$ & $29(91)$ & 0.38 \\
\hline Bystander CPR & $31(91)$ & $134(97)$ & $52(95)$ & $29(91)$ & 0.42 \\
\hline No-flow $\geq 10 \mathrm{~min}$ & $0(0)$ & $10(7)$ & $0(0)$ & $1(3)$ & 0.07 \\
\hline Pre-hospital low-flow (min) & $60[43-77]$ & $75[60-90]$ & 77 [65-99] & $60[48-70]$ & $<0.001$ \\
\hline Total low-flow (min) & $90[62-110]$ & 105 [88-125] & 119 [105-127] & 94 [81-130] & $<0.001$ \\
\hline Distance to center $\geq 100 \mathrm{~km}$ & $2(6)$ & $21(15)$ & $19(35)$ & $0(0)$ & 0.001 \\
\hline 30-day survival & $5(15)$ & $38(28)$ & $14(25)$ & $9(28)$ & 0.41 \\
\hline
\end{tabular}

Abbreviations: MCS Mechanical circulatory support; VT Ventricular tachycardia; VF Ventricular fibrillation; PEA Pulseless electrical activity; CPR Cardio pulmonary resuscitation

Values are stated as medians and interquartile range (IQR) or numbers and percentages. A p value of $<0.05$ is considered significant

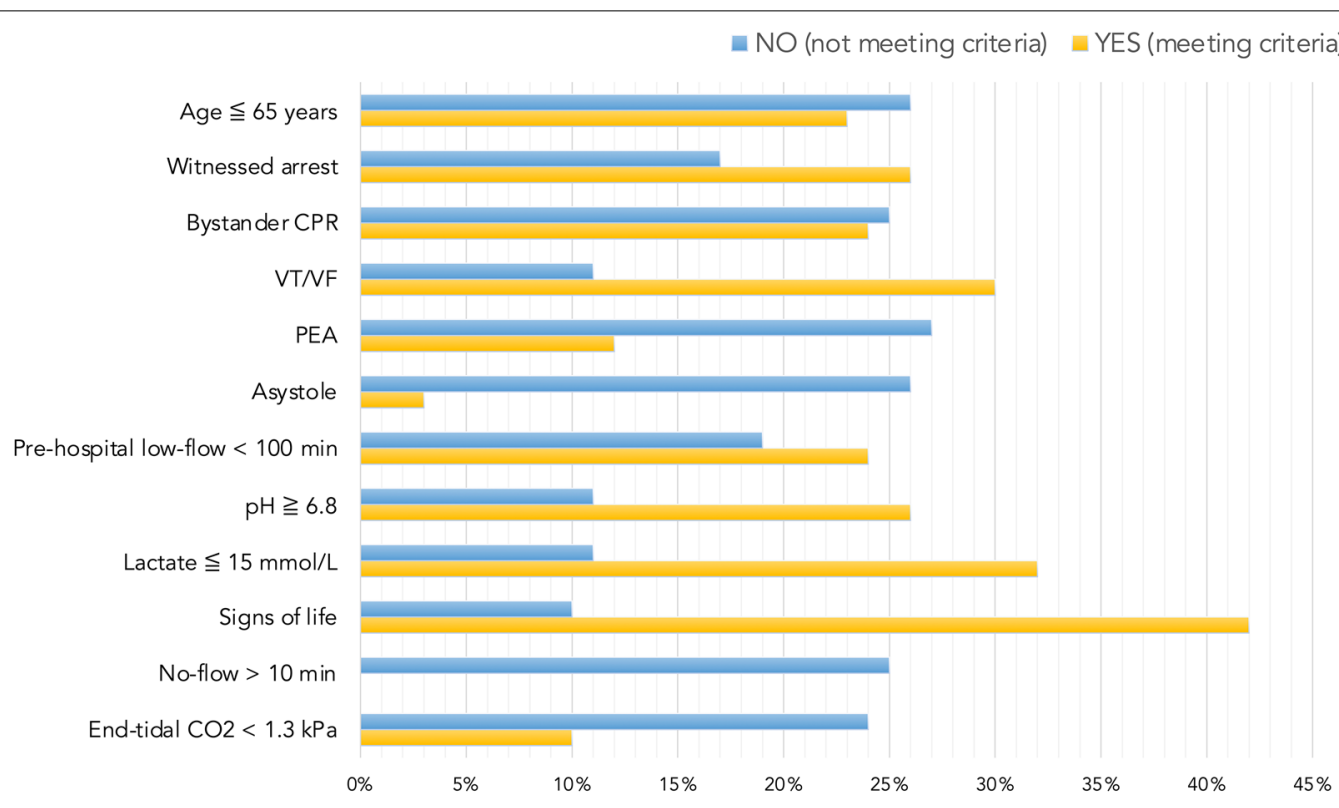

Survivors to discharge with CPC 1-2

Fig. 3 The impact of each selection criteria of the Danish national ECPR consensus in relation to survival to discharge with favorable neurological outcome (CPC 1-2). Survivors to discharge with CPC 1-2 in percentage when meeting selection criteria and failing to meet criteria of the national consensus

who failed to meet one or more of these parameters $(\mathrm{n}=134,52 \%)$ (Fig. 4). Thirty-day survival was $30 \%$ in patients who met the selection criteria compared with
$22 \%$ in patients who failed to meet one or more criteria $(\mathrm{p}=0.11)$.

A more refined assessment of selection criteria including parameters such as signs of life during CPR, 


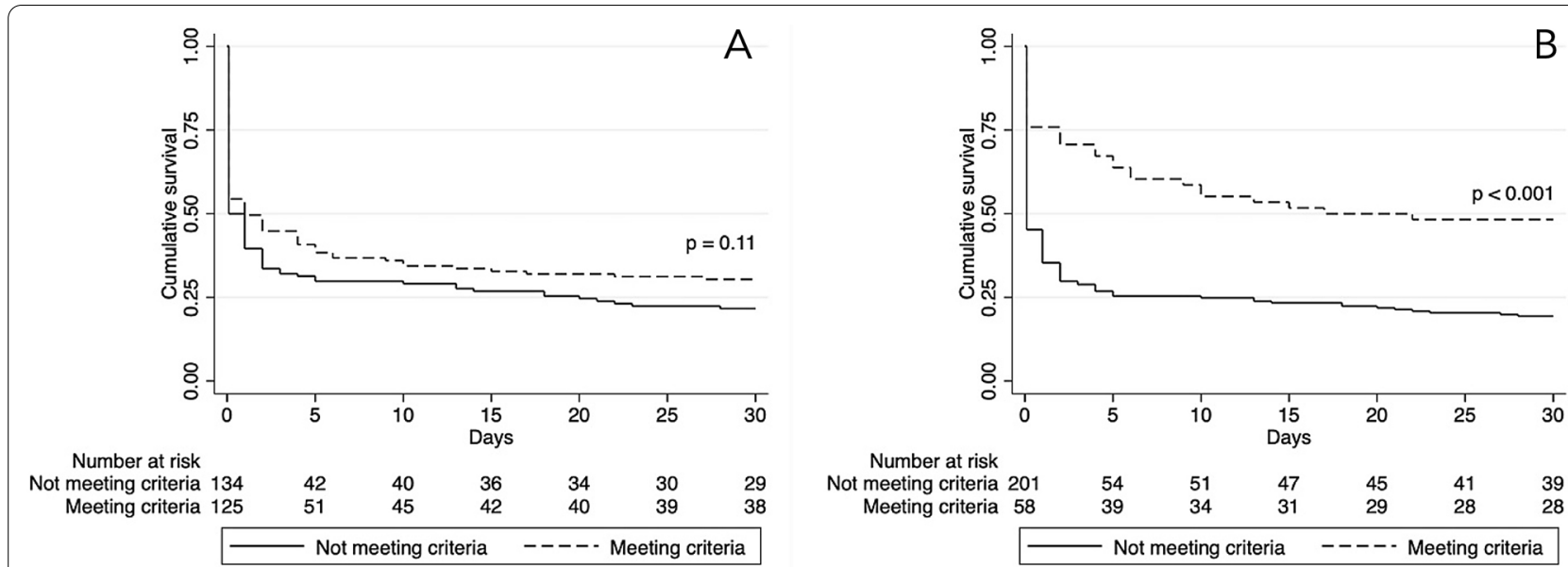

Fig. 4 Kaplan-Meier survival curve for patients meeting the selection criteria and patients failing to meet the criteria. a Consensus A (National consensus): Survival analysis between patients meeting the Danish national consensus selection criteria in regards to younger age $<65$ years, witnessed arrest, bystander CPR, initial shockable rhythm, no-flow $<10$ min and end-tidal $\mathrm{CO}_{2}<1.3 \mathrm{kPa}$, and patients failing to meet one or more criteria. $\mathbf{b}$ Consensus B (Extended version): Survival analysis based on a more refined assessment of selection criteria. Patients meeting all the selection criteria in the Danish national consensus and additionally one or more of following parameters: signs of life during $\mathrm{CPR}, \mathrm{pH}>6.8$, lactate $<15 \mathrm{mmol} / \mathrm{L}$ and a pre-hospital low-flow $<100 \mathrm{~min}$

pre-hospital low-flow $<100 \mathrm{~min}$, initial $\mathrm{pH}>6.8$ and lactate $\leq 15 \mathrm{mmol} / \mathrm{L}$ in addition to the consensus criteria (Consensus B) showed significantly higher 30-day survival rates in patients meeting one or more of the extended criteria than in patients failing to comply with the criteria ( $48 \%$ versus $19 \%, \mathrm{p}<0.001)$ (Fig. 4). However, this also implied that $58 \%(39 / 67)$ of the 30 -day survivors in this cohort would fail to meet the extended consensus.

\section{Discussion}

The present study is the first nationwide multicenter study of outcomes in patients receiving MCS for refractory OHCA in Denmark. The main findings showed that one in four MCS patients survive to hospital discharge with a good neurological outcome. Outcome was significantly associated with initial presenting rhythm, signs of life during CPR, transient ROSC, pre-hospital lowflow time, initial $\mathrm{pH}$ and lactate levels. By offering MCS only to patients meeting the strictest criteria, survival exceeded $48 \%$, but this occurred at the cost of withholding life-saving treatment in the majority of patients saved by MCS in the cohort. Thus, our data rightly questions the validity of stringent patient selection for MCS.

ECPR has emerged as a salvage therapy for patients suffering from refractory OHCA. Although resource demanding, ECPR has been shown to be both feasible and cost effective [13]. Moreover, recent small reports have described the potential of the Impella device as an alternative rescue therapy in cardiac arrest patients [7, 8]. Several previous observational studies have demonstrated encouraging survival rates and a favorable neurological outcome from applying strict inclusion and exclusion criteria in distinctive patient populations [1418]. The first randomized clinical trial recently published by Yannopoulos et al. (the ARREST trial) revealed superiority of ECMO-facilitated resuscitation with a survival rate of $43 \%$ compared with $7 \%$ with standard advanced life support [6]. Survival at six months was also greater in the ECMO group (hazard ratio (HR) 0.16, 95\% CI 0.06$0.41, \mathrm{p}=0.0001)$. Whereas the trial was well-designed and supports use of ECPR in refractory OHCA, apparent limitations are present as this was an open-labelled single-center study with a relatively small and highly selected patient population.

In Denmark, a number of initiatives to improve prehospital quality of care for OHCA patients have produced a remarkable increase in 30-day survival rates from $3.9 \%$ in 2001 to $16 \%$ in 2018 [19]. Concurrently, MCS with ECMO and in limited cases the Impella device, has been evolving steadily and is now an established treatment for selected patients with refractory OHCA in all Danish regions. However, given the formal inclusion and exclusion criteria defined in the Danish national ECPR consensus, one might assume that the results of our study would reflect a more homogeneous population. Despite our intention to select qualified candidates, violation of the national consensus was still seen in $52 \%$. In this population, the fatal consequence of treatment not being provided, opted some ECPR teams to perform MCS despite adverse conditions. Selection of appropriate candidates for MCS is evidently a challenge in real clinical practise. Despite growing interest in and a growing 
body of literature on MCS for refractory OHCA, robust evidence on patient eligibility is still lacking.

In the present study, the majority of patients treated with MCS were younger ( $<65$ years) in compliance with the national consensus. This may explain why no statistically significant difference was detected in age between survivors and non-survivors. One may have predicted a worse prognosis in patients above 65 years of age, but survival to hospital discharge with good neurological outcome was similar in this group compared with the younger population $<65$ years $(26 \%$ versus $23 \%)$. Previous studies have proposed advanced age as a predictor of a poor outcome in patients with ECPR [20], and some studies have even suggested an age of $>75$ years as a contraindication for ECPR [21], which is in line with our results. In our cohort, no one above 72 years of age survived to discharge. However, there is limited and conflicting evidence that older age is associated with poor outcome [22, 23]. The dilemma of initiating ECPR in the elderly remains controversial and more evidence is needed to confirm, whether to proceed or stop advanced life support based on age limits.

Pre-hospital parameters are crucial in the selection of suitable candidates for ECPR. Initial shockable rhythm, transient ROSC and signs of life during CPR are considered favorable prognostic factors in ECPR [24-26]. In a prospective registry study, Bougouin et al. compared conventional CPR with ECPR in 13,191 consecutive patients with OHCA [27]. Prognostic factors in the ECPR group comprised an initial shockable rhythm (OR 3.9, 95\% CI 1.5-10.3) and transient ROSC (OR 2.3, 95\% CI 1.1-4.7) prior to ECPR implementation. One of the main findings in our study was that patients with signs of life during CPR had a threefold higher survival rate than patients without signs of life during CPR. This is in correlation with a study recently published by Debaty et al. [28] The authors found that any signs of life before or during CPR substantially improved 30-day survival with favorable neurological outcome in a multivariable prognostic model (OR 7.35, 95\% CI 2.71-19.97). These results are supported by our data. Signs of life was a highly significant prognostic factor in relation to initial presenting rhythm and low-flow times. In the present cohort, a pre-hospital low-flow time $<60 \mathrm{~min}$ was associated with an increased survival rate; however, patients exceeding pre-hospital low-flow times $>80 \mathrm{~min}$ also had an advantageous outcome. Patients with pre-hospital low-flow times $>80 \mathrm{~min}$ had a higher rate of signs of life during CPR than patients with a pre-hospital low-flow time of 60-80 min. The presence of signs of life increased survival rates substantially in both groups. Collectively, these observations support the evidence of incorporating signs of life as an important factor in the selection of patients for ECPR. Our results suggest that prolonged resuscitation efforts in the field may not be futile, especially in patients presenting favorable circumstances such as signs of life and where ECPR can be established within a reasonable timeframe. The present findings do not allow us to determine whether any of the patients would have survived without MCS. However, the long total low-flow times observed makes this unlikely.

Historically, the arrest-to-perfusion time has been linked to survival $[16,18,29,30]$. Wengenmayer et al. reported that among 133 patients with cardiac arrest treated with ECPR, low-flow time was an independent predictor of mortality [30]. Bartos et al. demonstrated a significant association between time from arrest to sufficient ECPR flow and neurological outcome in a cohort of 160 patients [18]. These results are similar to ours. In the present study, hospitals serving patients in remote and rural areas had longer arrest-to-perfusion time due to longer distances to the invasive center. Implementation of systematic pre-hospital ECPR calls, more rapid allocation of helicopter-mediated transport and direct triage to the catheterization laboratory may improve the performance and facilitate a reduction in system delay for these patients. In this setting, pre-hospital ECPR may also shorten the interval from collapse to onset of ECPR [17].

The predictive value of $\mathrm{pH}$ and lactate levels in patients with cardiac arrest is well established. Controversy still exists regarding the ECPR population. In our study, initial arterial $\mathrm{pH}$ and lactate levels were found to be associated with mortality. This finding is consistent with previous findings [14, 31]. Jung et al. retrospectively reviewed 93 patients with cardiac arrest undergoing ECPR and found results similar to our results [32]. On the contrary, Leick et al. found no association between elevated lactate levels and mortality [33]. Our results support the inclusion of $\mathrm{pH}$ and lactate into our decision-making when considering patients for MCS, whereas specific cutoffs still need conformation in other cohorts. Importantly, a stringent use of $\mathrm{pH}>6.8$ and lactate $<15 \mathrm{mmol} / \mathrm{L}$ as selection criteria, may result in denying life-saving therapy to a considerable number of the survivors present in this cohort.

In the present study, we assessed pre-hospital and inhospital factors in relation to outcome, which may come in benefit for clinicians in the selection of appropriate candidates for MCS. High mortality rates were seen among patients with initial non-shockable rhythm, noflow times $>10 \mathrm{~min}$ and end-tidal $\mathrm{CO}_{2}<1.3 \mathrm{kPa}$. On the contrary, our results suggest that a more refined assessment of the inclusion criteria, comprising additional criteria such as signs of life during CPR and lactate levels, may improve survival rates in patients receiving MCS. Nevertheless, one must recognize that limiting patient 
selection to strict pre-defined criteria will inevitably exclude some patients in whom MCS would have bought valuable time until the reversible cause could be treated. The fact that the national consensus was violated in $52 \%$ of patients, of whom $20 \%$ survived to hospital discharge with a good neurological outcome in $94 \%$ of the cases, indicates that there must be room for individual decision-making, especially in the young patients. Patient selection for MCS continues to be a challenging part of real-world clinical practice and further randomized clinical trials are warranted.

\section{Limitations}

The present study has several limitations. Its retrospective nature makes it subject to patient selection bias. The national consensus was available and adopted to some extent in all centers. This produces risk of bias in the evaluation of the associations with outcome. Although we conducted a multicenter study using nationwide registry data, the heterogeneity of the study population with a mixed cohort of patients with OHCA hampers generalization of the results. Neurological outcome at hospital discharge is a fairly crude measure; it is, however, broadly used in cardiac arrest studies. Studies assessing longterm survival and neurological outcome are necessary.

\section{Conclusion}

Patients receiving MCS for refractory OHCA presented promising survival rates with a favorable neurological outcome at hospital discharge. Even though a more stringent patient selection with additional criteria may produce higher survival rates, this would also limit the number of candidates and possibly exclude half of the survivors from treatment, why optimization of the selection criteria is still of essence in the future.

\section{Abbreviations \\ CPC: Cerebral performance category; CPR: Cardiopulmonary resuscita- tion; ECMO: Extracorporeal membrane oxygenation; ECPR: Extracorporeal cardiopulmonary resuscitation; ICU: Intensive care unit; LUCAS: Lund university cardiopulmonary assist system; MCS: Mechanical circulatory support; OHCA: Out-of-hospital cardiac arrest; PEA: Pulseless electrical activity; ROSC: Return of spontaneous circulation; TTM: Targeted temperature management; VF: Ventricular fibrillation; VT: Ventricular tachycardia.}

\section{Supplementary Information}

The online version contains supplementary material available at https://doi. org/10.1186/s13054-021-03606-5.

Additional file 1. Table S1: National and regional indications for mechanical circulatory support in refractory normothermic cardiac arrest with presumed cardiac origin.
Additional file 2. Figure S1: National trend in the use of mechanical circulatory support for OHCA in Denmark.

Additional file 3. Figure S2: Kaplan-Meier survival curves of patients who had out-of-hospital cardiac arrest and received mechanical circulatory support.

Additional file 4. Figure S3: Kaplan-Meier survival curves stratified by groups.

\section{Acknowledgements}

Not applicable.

\section{Authors' contributions}

SRM, CS, SC, and CJT conceived and designed the study. SRM, LL, JBA, and EG collected data. SRM performed statistical analysis, interpreted the data, and drafted the manuscript. CS, SC and CJT supervised the study. All authors read and approved the final manuscript.

\section{Funding}

This work was supported by the Danish Heart Foundation

[20-R142-A9498-22178]; and Health Research Foundation of Central Denmark Region [R64-A3178-B1349]; and Danish Helicopter Emergency Medical Service Research Fund; and Aase og Ejnar Danielsens Fond; and Snedkermester Sophus Jacobsen og hustru Astrid Jacobsens Fond; and Henry og Astrid Møllers Fond; and a research grant from Aarhus University to Dr. Mørk; and Lundbeck Foundation [R186-2015-2132] to Dr. Hassager. None of the mentioned sources listed participated in design of the study, study collection, analysis, interpretation of data, or writing of the manuscript.

\section{Availability of data and materials}

The data underlying this article were provided by the administrative Regions of Denmark under license from the Danish Data Protection Agency and the Danish Patient Safety Authority and cannot be shared publicly due to Danish regulations for data protection. Data are however available from the authors upon reasonable request and with permission from the five administrative Regions of Denmark.

\section{Declarations}

\section{Ethical approval and consent to participate}

The study was conducted in accordance with the Declaration of Helsinki and approved by the Danish Data Protection Agency (Ref. 1-16-02-383-18) and the Danish Patient Safety Authority (Ref. 3-3013-2696/1). In Denmark, informed consent or ethical approval is not required for registry-based research.

\section{Consent for publication \\ Not applicable.}

\section{Competing interests}

Dr. Stengaard reports speaker's fees from Rosche Diagnostics, outside the submitted work. Dr. Møller reports personal fees and grants from Orion Pharma, Novartis, Astra Zeneca, Abbott and Abiomed and served at scientific advisory board for Boehringer Ingelheim, outside the submitted work. Dr. Freeman reports grants from St. Jude and Astra Zeneca and personal fees from Meril Lifesciences and Edwards Lifesciences, outside the submitted work. Dr. Hassager reports grants from the Lundbeck Foundation and speaker's honoraria from Abiomed, outside the submitted work. Dr. Kjaergaard reports non-financial participation in the advisory board for the CoCa Trial. Dr. Terkelsen is supported by an unrestricted research grant from the Danish Heart Foundation. The remaining authors have no conflicts of interest to declare.

\section{Author details}

${ }^{1}$ Department of Cardiology, Aarhus University Hospital, Palle Juul-Jensens Boulevard 99, 8200 Aarhus N, Denmark. ${ }^{2}$ Department of Cardiology, Odense University Hospital, Odense, Denmark. ${ }^{3}$ Department of Anaesthesiology and Intensive Care, Odense University Hospital, Odense, Denmark. ${ }^{4}$ Department of Thoracic and Vascular Surgery, Odense University Hospital, Odense, Denmark. ${ }^{5}$ Department of Anaesthesiology and Intensive Care, Aalborg University Hospital, Aalborg, Denmark. ${ }^{6}$ Department of Cardiology, Aalborg 
University Hospital, Aalborg, Denmark. ${ }^{7}$ Department of Anaesthesiology and Intensive Care, Aarhus University Hospital, Aarhus, Denmark. ${ }^{8}$ Department of Thoracic and Vascular Surgery, Aarhus University Hospital, Aarhus, Denmark. ${ }^{9}$ Cardiothorascic Anaesthesiology, Copenhagen University Hospital, Copenhagen, Denmark. ${ }^{10}$ Department of Cardiology, Copenhagen University Hospital, Copenhagen, Denmark. ${ }^{11}$ The Danish Heart Foundation, Copenhagen, Denmark.

Received: 23 March 2021 Accepted: 14 May 2021 Published online: 22 May 2021

\section{References}

1. Grasner JT, Wnent J, Herlitz J, Perkins GD, Lefering R, Tjelmeland I, Koster RW, Masterson S, Rossell-Ortiz F, Maurer H, Bottiger BW, Moertl M, Mols P, Alihodzic H, Hadzibegovic I, loannides M, Truhlar A, Wissenberg M, Salo A, Escutnaire J, Nikolaou N, Nagy E, Jonsson BS, Wright P, Semeraro F, Clarens C, Beesems S, Cebula G, Correia VH, Cimpoesu D, Raffay V, Trenkler S, Markota A, Stromsoe A, Burkart R, Booth S, Bossaert L. Survival after out-of-hospital cardiac arrest in Europe: results of the EuReCa TWO study. Resuscitation. 2020;148:218-26.

2. Haneya A, Philipp A, Diez C, Schopka S, Bein T, Zimmermann M, Lubnow M, Luchner A, Agha A, Hilker M, Hirt S, Schmid C, Muller T. A 5-year experience with cardiopulmonary resuscitation using extracorporeal life support in non-postcardiotomy patients with cardiac arrest. Resuscitation. 2012;83:1331-7.

3. Sakamoto T, Morimura N, Nagao K, Asai Y, Yokota H, Nara S, Hase M, Tahara Y, Atsumi T and Group S-JS. Extracorporeal cardiopulmonary resuscitation versus conventional cardiopulmonary resuscitation in adults with out-of-hospital cardiac arrest: a prospective observational study. Resuscitation. 2014;85:762-8.

4. Fjolner J, Greisen J, Jorgensen MR, Terkelsen CJ, Ilkjaer LB, Hansen TM, Eiskjaer H, Christensen S, Gjedsted J. Extracorporeal cardiopulmonary resuscitation after out-of-hospital cardiac arrest in a Danish health region. Acta Anaesthesiol Scand. 2017;61:176-85.

5. Dennis M, McCanny P, D'Souza M, Forrest P, Burns B, Lowe DA, Gattas D, Scott S, Bannon P, Granger E, Pye R, Totaro R, Sydney ERIG. Extracorporeal cardiopulmonary resuscitation for refractory cardiac arrest: A multicentre experience. Int J Cardiol. 2017;231:131-6.

6. Yannopoulos D, Bartos J, Raveendran G, Walser E, Connett J, Murray TA, Collins G, Zhang L, Kalra R, Kosmopoulos M, John R, Shaffer A, Frascone RJ, Wesley K, Conterato M, Biros M, Tolar J, Aufderheide TP. Advanced reperfusion strategies for patients with out-of-hospital cardiac arrest and refractory ventricular fibrillation (ARREST): a phase 2, single centre, openlabel, randomised controlled trial. Lancet. 2020;396:1807-16.

7. Vase H, Christensen S, Christiansen A, Therkelsen CJ, Christiansen EH, Eiskjaer H, Poulsen SH. The Impella CP device for acute mechanical circulatory support in refractory cardiac arrest. Resuscitation. 2017;112:70-4.

8. Panagides V, Vase H, Shah SP, Basir MB, Mancini J, Kamran H, Batra S, Laine M, Eiskjaer H, Christensen S, Karami M, Paganelli F, Henriques JPS and Bonello L. Impella CP Implantation during Cardiopulmonary Resuscitation for Cardiac Arrest: A Multicenter Experience. J Clin Med. 2021;10.

9. Danish National Consensus for ECPR (Danish Society of Cardiology). 2018:https://www.cardio.dk/media/com_reditem/files/customfield/item/ 6866/DCS\%20Holdningspapir\%201-18.pdf.

10. Mork SR, Frederiksen CA, Nielsen RR, Lichscheidt E, Christensen S, Greisen JR, Tang M, Vase H, Logstrup BB, Mellemkjaer S, Wiggers HS, Molgaard H, Poulsen $\mathrm{SH}$, Terkelsen CJ, Eiskjaer H. A systematic approach to weaning from extracorporeal membrane oxygenation in patients with refractory cardiac failure. Acta Anaesthesiol Scand. 2021;00:1-8.

11. Idris AH, Bierens J, Perkins GD, Wenzel V, Nadkarni V, Morley P, Warner DS, Topjian A, Venema AM, Branche CM, Szpilman D, Morizot-Leite L, Nitta M, Lofgren B, Webber J, Grasner JT, Beerman SB, Youn CS, Jost U, Quan L, Dezfulian C, Handley AJ, Hazinski MF. 2015 revised Utstein-style recommended guidelines for uniform reporting of data from drowningrelated resuscitation: An ILCOR advisory statement. Resuscitation. 2017;118:147-58

12. Brain Resuscitation Clinical Trial IISG. A randomized clinical study of a calcium-entry blocker (lidoflazine) in the treatment of comatose survivors of cardiac arrest. N Engl J Med. 1991;324:1225-31.
13. Matsuoka Y, Goto R, Atsumi T, Morimura N, Nagao K, Tahara Y, Asai Y, Yokota H, Ariyoshi K, Yamamoto Y, Sakamoto T and Group S-JS. Costeffectiveness of extracorporeal cardiopulmonary resuscitation for out-of-hospital cardiac arrest: A multi-centre prospective cohort study. Resuscitation. 2020;157:32-8.

14. Debaty G, Babaz V, Durand M, Gaide-Chevronnay L, Fournel E, Blancher M, Bouvaist H, Chavanon O, Maignan M, Bouzat P, Albaladejo P, Labarere J. Prognostic factors for extracorporeal cardiopulmonary resuscitation recipients following out-of-hospital refractory cardiac arrest. A systematic review and meta-analysis. Resuscitation. 2017;112:1-10.

15. Dennis M, Buscher H, Gattas D, Burns B, Habig K, Bannon P, Patel S, Buhr H, Reynolds C, Scott S, Nair P, Hayman J, Granger E, Lovett R, Forrest P, Coles J, Lowe DA, Sydney ERIG. Prospective observational study of mechanical cardiopulmonary resuscitation, extracorporeal membrane oxygenation and early reperfusion for refractory cardiac arrest in Sydney: the 2CHEER study. Crit Care Resusc. 2020;22:26-34.

16. Lunz D, Calabro L, Belliato M, Contri E, Broman LM, Scandroglio AM, Patricio D, Malfertheiner M, Creteur J, Philipp A, Taccone FS, Pappalardo F. Extracorporeal membrane oxygenation for refractory cardiac arrest: a retrospective multicenter study. Intensive Care Med. 2020;46:973-82.

17. Lamhaut L, Hutin A, Puymirat E, Jouan J, Raphalen JH, Jouffroy R, Jaffry M, Dagron C, An K, Dumas F, Marijon E, Bougouin W, Tourtier JP, Baud F, Jouven X, Danchin N, Spaulding C, Carli P. A Pre-Hospital Extracorporeal Cardio Pulmonary Resuscitation (ECPR) strategy for treatment of refractory out hospital cardiac arrest: an observational study and propensity analysis. Resuscitation. 2017;117:109-17.

18. Bartos JA, Grunau B, Carlson C, Duval S, Ripeckyj A, Kalra R, Raveendran G, John R, Conterato M, Frascone RJ, Trembley A, Aufderheide TP, Yannopoulos D. Improved survival with extracorporeal cardiopulmonary resuscitation despite progressive metabolic derangement associated with prolonged resuscitation. Circulation. 2020;141:877-86.

19. Ringgren KB, Christensen HC, Schønau L, Lippert FK, Folke F, Christensen EF, Hendriksen OM, Nielsen PS, Hansen PA, Mikkelsen S and TorpPedersen C. Danish Cardiac Arrest Registry 2001-2018. (2018);22 Mar 2021:https://hjertestopregister.dk/wp-content/uploads/2019/11/DanskHjertestopregister-2018-2.pdf.

20. de Waha S, Fuernau G, Eitel I, Desch S, Thiele H. Long-term prognosis after extracorporeal life support in refractory cardiogenic shock-results from a real-world cohort. Eurolntervention. 2016;12:414.

21. Klinzing S, Wenger U, Steiger P, Starck CT, Wilhelm M, Schuepbach RA, Maggiorini M. External validation of scores proposed for estimation of survival probability of patients with severe adult respiratory distress syndrome undergoing extracorporeal membrane oxygenation therapy: a retrospective study. Crit Care. 2015;19:142.

22. Pontailler M, Demondion P, Lebreton G, Golmard JL, Leprince P. Experience with extracorporeal life support for cardiogenic shock in the older population more than 70 years of age. ASAIO J. 2017;63:279-84

23. Saito S, Nakatani T, Kobayashi J, Tagusari O, Bando K, Niwaya K, Nakajima H, Miyazaki S, Yagihara T, Kitamura S. Is extracorporeal life support contraindicated in elderly patients? Ann Thorac Surg. 2007;83:140-5.

24. Stub D, Nehme Z, Bernard S, Lijovic M, Kaye DM, Smith K. Exploring which patients without return of spontaneous circulation following ventricular fibrillation out-of-hospital cardiac arrest should be transported to hospital? Resuscitation. 2014;85:326-31.

25. Ko RE, Ryu JA, Cho YH, Sung K, Jeon K, Suh GY, Park TK, Lee JM, Song YB, Hahn JY, Choi JH, Choi SH, Gwon HC, Carriere KC, Ahn J, Yang JH. The differential neurologic prognosis of low-flow time according to the initial rhythm in patients who undergo extracorporeal cardiopulmonary resuscitation. Resuscitation. 2020;148:121-7.

26. Yannopoulos D, Bartos JA, Raveendran G, Conterato M, Frascone RJ, Trembley A, John R, Connett J, Benditt DG, Lurie KG, Wilson RF, Aufderheide TP. Coronary artery disease in patients with out-of-hospital refractory ventricular fibrillation cardiac arrest. J Am Coll Cardiol. 2017;70:1109-17.

27. Bougouin W, Dumas F, Lamhaut L, Marijon E, Carli P, Combes A, Pirracchio R, Aissaoui N, Karam N, Deye N, Sideris G, Beganton F, Jost D, Cariou A, Jouven X. Sudden Death Expertise Center I. Extracorporeal cardiopulmonary resuscitation in out-of-hospital cardiac arrest: a registry study. Eur Heart J. 2020;41:1961-71.

28. Debaty G, Lamhaut L, Aubert R, Nicol M, Sanchez C, Chavanon O, Bouzat P, Durand M, Vanzetto G, Hutin A, Jaeger D, Chouihed T and Labarere J. Prognostic value of signs of life throughout cardiopulmonary 
resuscitation for refractory out-of-hospital cardiac arrest. Resuscitation 2021.

29. Otani T, Sawano H, Natsukawa T, Nakashima T, Oku H, Gon C, Takahagi $\mathrm{M}$, Hayashi Y. Low-flow time is associated with a favorable neurological outcome in out-of-hospital cardiac arrest patients resuscitated with extracorporeal cardiopulmonary resuscitation. J Crit Care. 2018;48:15-20.

30. Wengenmayer T, Rombach S, Ramshorn F, Biever P, Bode C, Duerschmied D, Staudacher DL. Influence of low-flow time on survival after extracorporeal cardiopulmonary resuscitation (eCPR). Crit Care. 2017;21:157.

31. D'Arrigo S, Cacciola S, Dennis M, Jung C, Kagawa E, Antonelli M, Sandroni C. Predictors of favourable outcome after in-hospital cardiac arrest treated with extracorporeal cardiopulmonary resuscitation: a systematic review and meta-analysis. Resuscitation. 2017;121:62-70.

32. Jung C, Bueter S, Wernly B, Masyuk M, Saeed D, Albert A, Fuernau G, Kelm M and Westenfeld R. Lactate clearance predicts good neurological outcomes in cardiac arrest patients treated with extracorporeal cardiopulmonary resuscitation. J Clin Med. 2019;8.

33. Leick J, Liebetrau C, Szardien S, Fischer-Rasokat U, Willmer M, van Linden A, Blumenstein J, Nef H, Rolf A, Arlt M, Walther T, Hamm C, Mollmann H. Door-to-implantation time of extracorporeal life support systems predicts mortality in patients with out-of-hospital cardiac arrest. Clin Res Cardiol. 2013:102:661-9.

\section{Publisher's Note}

Springer Nature remains neutral with regard to jurisdictional claims in published maps and institutional affiliations.
Ready to submit your research? Choose BMC and benefit from:

- fast, convenient online submission

- thorough peer review by experienced researchers in your field

- rapid publication on acceptance

- support for research data, including large and complex data types

- gold Open Access which fosters wider collaboration and increased citations

- maximum visibility for your research: over 100M website views per year

At BMC, research is always in progress.

Learn more biomedcentral.com/submissions 